\title{
Cytokines Levels in Children Affected by Atopic and Nonatopic Eczema
}

\author{
Giampaolo Ricci ${ }^{*}, 1$, Annalisa Patrizi ${ }^{2}$, Federica Bellini $^{1}$, Elisabetta Calamelli ${ }^{1}$, Valeria Dell’Omo ${ }^{1}$, \\ Barbara Bendandi ${ }^{1}$ and Massimo Masi ${ }^{1}$
}

\author{
${ }^{I}$ Department of Paediatrics, S. Orsola-Malpighi Hospital, University of Bologna, Bologna, Italy \\ ${ }^{2}$ Department of Clinical and Experimental Medicine, Division of Dermatology, S. Orsola-Malpighi Hospital University \\ of Bologna, Bologna, Italy
}

\begin{abstract}
Patients with atopic eczema present higher serum levels of total $\operatorname{IgE}$ and different pattern of cytokines, compared to nonatopic eczematous patients. This study aimed to evaluate serum levels of IL-2, IL-4, IL-5, IL-10, IFN $\gamma$, TNF $\alpha$ in eczematous children in relation to atopic and nonatopic form. We enrolled 45 eczematous children and 12 controls. Total IgE and specific IgE against principal food and inhalant allergens were evaluated by UniCap1000 and levels of cytokines by Cytometric Bead Array System. The geometric means of levels of IL-4 were higher in eczematous patients than controls $(P=0.036)$. Serum levels of IL-10 and IFN $\gamma$ were higher in nonatopic eczematous children than in atopic eczematous patients and controls $(P=0.004, P=0.003)$. Our data confirm that cytokines may play an important role in the pathogenesis of eczema: nonatopic eczema seems to be characterized by increased levels of IL-10 and IFN $\gamma$ compared to atopic form.
\end{abstract}

Keywords: Atopic eczema, childhood, cytokines, IL-10, IFN $\gamma$, nonatopic eczema.

\section{INTRODUCTION}

Eczema is a chronic inflammatory skin disorder characterized by pruritic chronic lesions. Two subsets of eczema have been described: $70-80 \%$ of eczematous patients present atopic form, with elevated serum IgE and allergic sensitization, whereas $20-30 \%$ of patients exhibit nonatopic form, with normal serum IgE levels and lack allergen-specific sensitisation.

Some immunological differences between atopic eczema and the nonatopic type have been observed in the cytokine pattern of peripheral blood and in the skin lesions, also by phenotyping characterization of epidermal dendritic cells, but few data are available [1].

Th2 cells play a key role in pathogenesis of eczema, this notion is supported by the presence of blood eosinophilia and enhanced serum IgE levels in the majority of patients affected, but recent studies suggests that both Th1 and Th2 cells may play roles in the pathogenesis of eczema. Novak et al. [1] show patients with atopic eczema have increased serum levels of IL-4, IL-5, while IL-13 seem to prevail in nonatopic form. Instead, Akdis et al. [2] show nonatopic form, compared with atopic form express significantly lower levels of IL-4 and IL-13 in their skin and and peripheral blood. Shimada et al. [3] investigated serum levels of Th2 and Th1 chemokine pattern in patients affected by atopic eczema compared with patients with contact dermatitis and normal controls; serum chemokine levels were examined in 55 patients ( 22 females, 33 males, mean age: 23 years). They demonstrated increased serum levels of Th2 but also Th1 chemokines in patients affected by atopic eczema compared

*Address correspondence to this author at the Department of Paediatrics, S. Orsola-Malpighi Hospital University of Bologna, Bologna, Italy;

E-mail: giampaolo.ricci@unibo.it with normal control subjects, suggesting that both Th1 and Th2 chemokines may be related to the development of this condition. Katsunuma et al. [4] investigated the relationship between Th1/Th2 serum cytokines and severity of eczema. In particular they assessed the transcription and production of IFN $\gamma$ and IL-5 in peripheral blood mononuclear cells of 29 subjects: 17 patients affected by severe eczema (mean age: 15 years), 4 mild eczema (mean age: 25.8 years), 8 healthy nonatopic controls (mean age: 27.4 years). The study evidenced decreased levels of IFN $\gamma$ in severe atopic eczema, suggesting that decreased production of this chemokine may account for the abnormal immunopathogenesis of severe, intractable eczema.

Data from skin biopsies obtained from uninvolved skin of eczematous patients indicate that acute skin lesions contain significantly more cells producing IL-4, IL-5 and IL-13, but not IFN $\gamma$ compared with chronic lesions [5]. In chronic lesions cells expressing IL-4 and IL-13 were significantly decreased, while cells expressing IL-5 and IFN $\gamma$ were increased. Antunez et al. [6] evaluated serum cytokines levels in patients with acute and chronic eczematous lesions; the study showed an increased percentage of $\mathrm{T}$ cells secreting IL-13, IL-4 in peripheral blood of patients with acute lesions there, increased serum levels of TNF $\alpha$ in those with chronic lesions. Cutaneous Tcells of patients with nonatopic form produce similar amounts of IL-5 and IFN $\gamma$, but less of IL-4 and IL-13 than cells of atopic patients. This distinct cytokine pattern might be both cause and effect of the lower IgE levels found in patients with nonatopic eczema. Many studies $[7,8]$ have showed an increased expression of IL-10 in skin lesions of patients with nonatopic eczema, moreover Shin at al. [9] showed a correlation between increased serum levels of IL-10 and decreased total IgE among eczematous patients, suggesting a probably association between this type of eczema and increased levels of IL-10. A recent study by Jacobi [10] demonstrated that targeted therapeutic approaches, like 
inhibition of TNF $\alpha$ cytokine that can be detected in high concentrations in skin and serum of patients with eczema maybe a novel therapeutic option, suggesting a role of this chemokine in pathogenesis of eczema.

The aim of our study was to evaluate serum levels of IL2 , IL-4, IL-5, IL-10, IFN $\gamma$, TNF $\alpha$ in patients affected by eczema and their relation to atopic and nonatopic form.

\section{MATHERIALS AND METHODOLOGY}

We studied 45 children (mean age: 2,5 years) affected by eczema who consecutively referred to our Centre. The diagnosis was made on the basis of Hanifin and Rajka's criteria; the evaluation of the severity of the disease was made using the SCORAD index [11]. Patients with a SCORAD $<25$ were considered with mild eczema, 25-50 moderate eczema and $>50$ severe eczema.

Total IgE and specific IgE antibodies against principal food (egg, cow's milk, wheat, peanut, fish) and inhalant allergens (grass pollen, D. Pteronyssinus, D. Farinae, cat, dog) were evaluated by UniCap 1000 System (Phadia, Sweden). We have considered sensitized patients with specific IgE levels $>0.35 \mathrm{Ku} / \mathrm{L}$. Atopic eczema was characterized by the presence of $\mathrm{sIgE}$ against food or inhalant allergens or by elevated serum total IgE levels, according to the WAO nomenclature [12].

Of the 45 children with eczema consecutively enrolled, $10(22 \%)$ were affected by nonatopic eczema, 35 (78\%) were affected by atopic eczema. Twelve healthy, non allergic children were designed as the control group. There were no differences in the age and clinical severity between the two groups of eczematous patients.

Serum levels of IL-2, IL-4, IL-5, IL-10, IFN $\gamma$, TNF $\alpha$ were examined by Cytometric Bead Array System that involve flow cytometry (CBA; Human Inflammation Kit, $\left.\mathrm{B} \& \mathrm{D}^{\mathrm{TM}}\right)$, which provides the opportunity to perform multiplex cytokine assay in a single analysis. This technique combines flow cytometry with traditional sandwich enzymelinked immunosorbent assay (ELISA), as each bead is analogous to one coated well in an ELISA. The CBA technique uses different light intensities to label the desired molecule and the flow cytometer is then used to analyse the light intensity that reflects the concentration of each cytokine.

Cytokines levels in serum of patients with eczema were compared with cytokines levels examined in the serum of control group.

\section{Statistical Methods}

The Statistical Package for Social Science (SPSS/PC; SPSS Inc., Chicago, IL, USA) was used for statistical analysis. The Student's t-test was used to decide the significance of the difference between the groups. Data were analyzed by looking for linear correlations between SCORAD and serum levels of cytokines and total IgE. Results were considered as statistically significant for $P \leq 0.05$.

\section{Ethical Consideration}

This research was conducted in accordance with the principles of the Declaration of Helsinki. Written informed con- sent was obtained from parents before the children were included in the study.

\section{RESULTS}

Ten patients $(22 \%)$ were affected by mild eczema, 33 $(73 \%)$ were affected by moderate eczema and $2(5 \%)$ by severe eczema. No difference in clinical severity between children affected by atopic and nonatopic eczema was found (Table 1). Fourteen patients with atopic eczema presented sIgE against foods and 23 were sensitized to inhalant allergens. The number of children with atopic eczema $(n=35)$ with specific IgE level $>0.35 \mathrm{kU} / \mathrm{L}$ against principal food and inhalant allergens are described in Table 2. The geometric means (GM) of serum cytokines levels in patients with eczema were higher than those found in normal controls; in particular serum levels of IL-4 were significantly higher in patients with eczema) than controls $(2.67 \mathrm{pg} / \mathrm{ml}$ vs 0.23 $\mathrm{pg} / \mathrm{ml} ; P=0.036)$. Serum levels of IL-10 and IFN $\gamma$ in children with nonatopic eczema were significantly higher $(P=$ $0.004, P=0.003$ ) than those found in children affected by atopic eczema and controls (Table 3, Fig. (1)).

A statistically significant correlation was found between SCORAD index and IL-5 ( $\mathrm{R}=0.3 ; P=0.016$; Fig. (2)). A statistically significant correlation was found between total $\mathrm{IgE}$ and IL-5 ( $\mathrm{R}=0.46 ; P=0.01)$.

No association was found between levels of sIgE against principal foods and inhalants and cytokines levels.

Table 1. SCORAD Index [11] in 45 Children (Mean Age: 2.5 Years Old) with Atopic $(n=35 ; 78 \%)$ and Nonatopic Eczema $(n=10 ; 22 \%)$. Patients with a SCORAD Index $<25$ were Considered with Mild Eczema, 25-50 Moderate Eczema and $>50$ Severe Eczema

\begin{tabular}{|c|c|c|c|}
\hline $\begin{array}{c}\text { SCORAD } \\
\text { INDEX }\end{array}$ & $\begin{array}{c}\text { All Children } \\
(\mathbf{n}=\mathbf{4 5})\end{array}$ & $\begin{array}{c}\text { Nonatopic } \\
\text { Eczema }(\mathbf{n}=\mathbf{1 0})\end{array}$ & $\begin{array}{c}\text { Atopic Eczema } \\
(\mathbf{n}=\mathbf{3 5})\end{array}$ \\
\hline \hline Mild $(<25)$ & $10(22 \%)$ & $2(20 \%)$ & $8(23 \%)$ \\
\hline Moderate $(25-50)$ & $33(73 \%)$ & $8(80 \%)$ & $25(72 \%)$ \\
\hline Severe $(>50)$ & $2(5 \%)$ & $0(0 \%)$ & $2(5 \%)$ \\
\hline
\end{tabular}

\section{DISCUSSION}

Research during the last decade has estabilished that several abnormalities in soluble factors, cellular characteristics, and other mediators in the blood are characteristic of the complex pathogenesis of eczema. Atopy is understood to be an imbalance between the Th2 and Th1 type immune responses, with the cutaneous inflammatory response in eczema being at least partly mediated by Th2 cytokines $[1,13$, 14]. Our data showed all patients affected by eczema present serum levels of IL-4, IL-5, IL-2, IL-10 higher than normal controls, confirming that Th2 cells play an important role in the pathogenesis of this form. Katsunuma et al. [4] assessed the transcription and production of IFN $\gamma$ and IL-5 in peripheral blood mononuclear cells of patients affected by severe eczema. They showed an opposite relation between serum levels of IFN $\gamma$ and severity of lesions suggesting that production of this cytokine may account for the abnormal immunopathogenesis of severe, intractable eczema. No correla- 
Table 2. Number of Children with Atopic Eczema (n=35) with Specific IgE Level $>0.35 \mathrm{kU} / \mathrm{L}$ Against Principal Food and Inhalant Allergens Tested

\begin{tabular}{|c|c|}
\hline Allergen & $\begin{array}{c}\text { Number of Children with } \\
\text { Specific IgE Level } \mathbf{0 . 3 5} \mathbf{~ k U} / \mathbf{L}\end{array}$ \\
\hline \hline Food Allergen & \\
\hline Egg & 9 \\
\hline Milk & 8 \\
\hline Peanut & 2 \\
\hline Fish & 1 \\
\hline Wheat & 1 \\
\hline Inhalant Allergen & 12 \\
\hline P. Pratense & 10 \\
\hline Cat Dander & 9 \\
\hline C. Dactylon & 9 \\
\hline D. Pteronyssinus & 9 \\
\hline D. Farinae & \\
\hline
\end{tabular}

Table 3. SCORAD Index, Total IgE Levels (Geometric Mean) and Serum Cytokines Levels (Geometric Mean) in 45 Children with Eczema (35 Cases of Atopic Eczema, 10 Nonatopic Eczema) and 12 Controls

\begin{tabular}{|c|c|c|c|}
\hline & $\begin{array}{l}\text { Nonatopic Eczema } \\
\text { (10 cases) }\end{array}$ & $\begin{array}{l}\text { Atopic Eczema } \\
\quad(35 \text { cases })\end{array}$ & $\begin{array}{l}\text { Control Group } \\
\text { (12 Cases) }\end{array}$ \\
\hline SCORAD & 32.3 & 33 & - \\
\hline $\operatorname{IgE}(\mathrm{kU} / \mathrm{L})$ & 31.2 & 408 & 25 \\
\hline IFN $\gamma(\mathrm{pg} / \mathrm{ml})$ & $2.52 * \dagger$ & $0.55 *$ & $0.58 \dagger$ \\
\hline TNF $\alpha(p g / m l)$ & 5.22 & 1.33 & 2.97 \\
\hline IL-10 (pg/ml) & $7.42 \S \ddagger$ & $2.53 \S$ & $1.28 \dagger$ \\
\hline IL-5 (pg/ml) & 1.67 & 1.73 & 0.22 \\
\hline IL-4 (pg/ml) & 2.13 & 0.54 & 0.23 \\
\hline IL-2 (pg/ml) & 1.32 & 0.41 & 0.25 \\
\hline
\end{tabular}

tion was found between the levels of IL-5 and severity of eczema. Our data, in contrast, show a statistically significant correlation between SCORAD index and IL-5 $(\mathrm{R}=0.3$, $P=0.016$ ), and between serum levels of IL-5 and total IgE; no correlation between severity of eczema and other interleukines considered. Moreover a significant correlation was found between IL-2 and total IgE levels, confirming that Th1 mechanism seems to take part in pathogenesis of eczema [15].

Our study show serum levels of IL-10, TNF $\alpha$, IFN $\gamma$ and IL-4 in patients with nonatopic eczema higher than those found in patients affected by atopic eczema, in particular serum levels of IL-10, and IFN $\gamma$ in patients with nonatopic eczema seem to be significantly higher than those found in patients affected by atopic eczema and controls $(P=0.004)$, in according to Novak and Bieber [1] that showed elevated serum IL-4 and IL-13 levels in this form suggesting the predominance of an immune response of Th2 type in this variant, but in contrast to Akdis et al. [2].

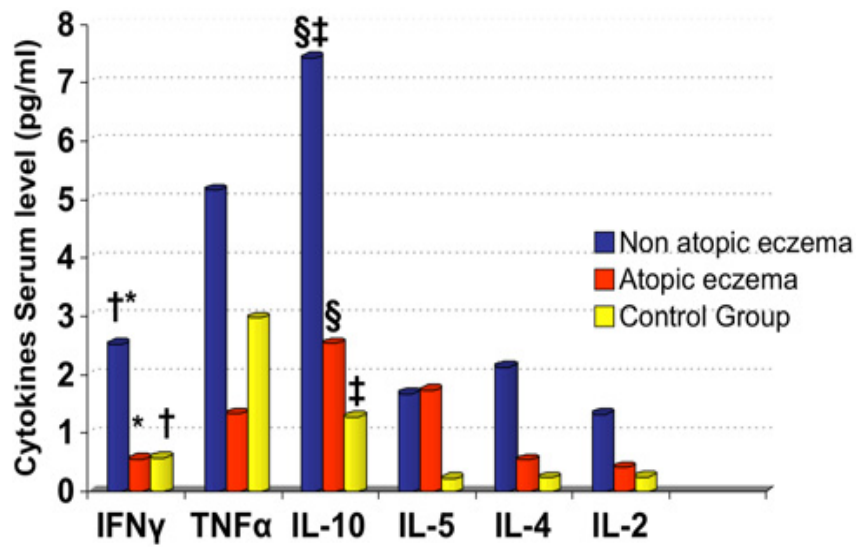

Fig. (1). Serum cytokines levels (geometric mean) in 45 children with eczema (35 cases of atopic eczema, 10 nonatopic eczema) and 12 controls. $* P=0.004 ; \dagger P=0.004 ; \S P=0.004 ; \dagger P=0.003$.

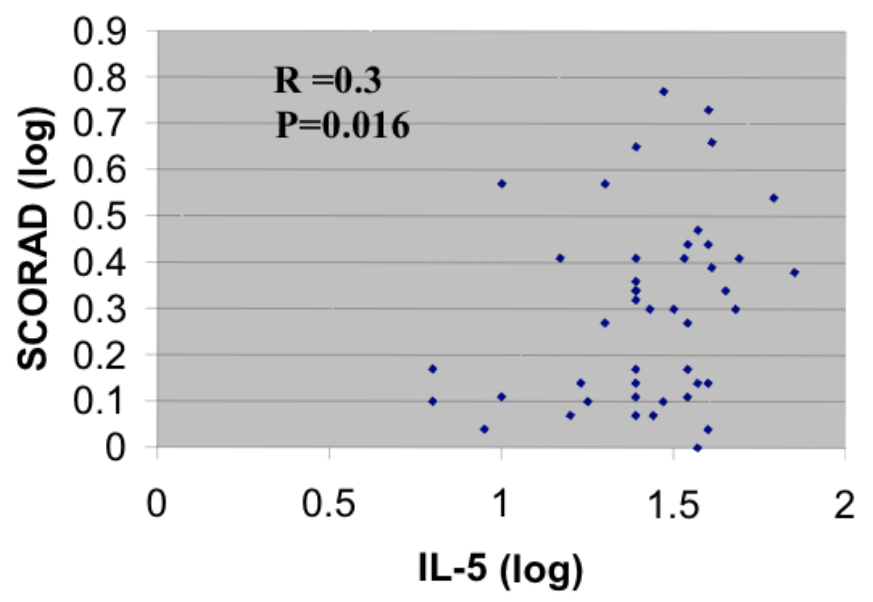

Fig. (2). Correlation between SCORAD index (log) and IL-5 (log) serum level in 45 children (mean age: 2.5 years old) with atopic $(\mathrm{n}=35 ; 78 \%)$ and nonatopic eczema $(\mathrm{n}=10 ; 22 \%)$.

Leung et al. [7] showed an increased expression of IL-10 in skin lesions of patients with nonatopic eczema compared with patients affected by psoriasis and controls, suggesting a probably association between nonatopic form of eczema and serum levels of IL-10. Shin at al. [9] scrutinized the single nucleotide polymorphisms in the IL-10 gene in serum of 334 patients (mean age: 28.9 years) affected by eczema. Subjects were categorized into three groups: low IgE group whose serum total IgE concentration was $<165 \mathrm{IU} / \mathrm{ml}$, intermediate group whose serum total $\operatorname{IgE}$ concentration was between 165 and $1500 \mathrm{UI} / \mathrm{ml}$, and high IgE group whose serum total $\mathrm{IgE}$ concentration was higher than $1500 \mathrm{UI} / \mathrm{ml}$. Logistic regression analyses were performed with single polymorphisms and aplotypes to determinate their association with level of serum total IgE. The study demonstrated that the inhibition of innate immunity by increased IL-10 production might be associated with decreased total serum IgE levels among eczematous patients, suggesting an inverse association between IL-10 production and total serum IgE levels. 
Howell et al. [16] observed significantly increased levels of IL-10 in skin lesions of patients affected by nonatopic eczema; using primary keratinocytes they found that the deficiency in anti-microbial peptide (AMP) expression is an acquired defect and showed that neutralizing antibodies to IL-10 augmented the production of TNF $\alpha$ and IFN $\gamma$ by peripheral blood mononuclear cell from eczematous patients, suggesting that increased levels of IL-10 may contribute to the AMP deficiency by reducing cytokines that induce AMP. According to Leung et al. [7] our data show increased serum IL-10 levels in patients with eczema, in particular serum levels were significantly higher in nonatopic form $(P=$ $0.004)$ than atopic form and controls $(P=0.003)$. No significant association was found between total serum IgE levels and IL-10. In contrast to Howell et al. [16] our data demonstrate that serum IFN $\gamma$ levels in patients with nonatopic eczema were significantly higher than those found in patients affected by atopic eczema and controls, suggesting a probably association between IL-10, IFN $\gamma$ levels and nonatopic form.

Our results show increased serum levels of $\mathrm{TNF} \alpha$ in eczematous patient, in particular higher levels in nonatopic form; the importance of this cytokine has been investigated by Jacobi et al. [10]. In a recent study they demonstrated that TNF $\alpha$ can be detected in high concentrations in skin and serum of patients with eczema. They suggest that targeted therapeutic approaches, like inhibition of $\mathrm{TNF} \alpha$ cytokine, that may be a novel therapeutic option in patients affected by severe eczema, suggesting the importance of this chemokine in pathogenesis of eczema, but few data are avaible.

We conclude that immunological differences can been detected in peripheral blood of patients affected by atopic and nonatopic eczema, in particular Th2 cells seem to detect a key role in the pathogenesis of atopic form, while nonatopic form seem to be characterized by Th1/Th2 mechanisms. Nevertheless further studies are necessary to clear the complex pathogenesis of nonatopic eczema.

\section{REFERENCES}

[1] Novak N, Bieber T. Allergic and nonallergic forms of atopic diseases. J Allergy Clin Immunol 2003; 112: 252-62.
[2] Akdis CA, Akdis M, Simon D, et al. Role of T cells and cytokines in the intrinsic form of atopic dermatitis. Curr Probl Dermatol 1999; 28: 37-44.

[3] Shimada Y, Takehara K, Sato S. Both Th2 and Th1 chemokines (TARC/CCL17, MDC/CCL22, and Mig/CXCL9) are elevated in sera from patients with atopic dermatitis. J Dermatol Sci 2004; 34 : 201-8.

[4] Katsunuma T, Kawahara H, Yuki K, et al. Impaired interferon gamma production in a subset population of severe atopic dermatitis. Int Arch Allergy Immunol 2004; 134: 240-7.

[5] Harakawa S, Hatano Y, Katagiri K. Differential expression of mRNA for Th1 and Th2 cytokine-associated transcription factors and suppressor of cytokine signalling in peripheral blood mononuclear cells of patients with atopic dermatitis. Clin Exp Immunol 2004; 135: 505-10.

[6] Antunez C, Torres MJ, Mayorga C, et al. Different cytokine production and activation marker profiles in circulating cutaneous lymphocyte associated antigen $\mathrm{T}$ cells from patients with acute or chronic atopic dermatitis. Clin Exp Allergy 2004; 34: 559-66.

[7] Leung DYM, Novak N, Boguniewicz M, et al. Elevated levels of IL-10 in intrinsic (IAD) and extrinsic atopic dermatitis (EAD) is associated with deficiency in antimicrobial peptide (AMP) production. J Allergy Clin Immunol 2004; 113: S96. 10.

[8] Asadullah K, Sterry W, Volk HD. Interleukin-10 therapy: review of a new approach. Pharmacol Rev 2003; 55: 241-69.

[9] Shin HD, Park BL, Kim LH, et al. Interleukin 10-aplotype associated with total serum $\mathrm{IgE}$ in atopic dermatitis patients. Allergy 2005; 60: 1146-51

[10] Jacobi A, Schuler G, Hertl M. Long term efficacy and safety of $\mathrm{TNF} \alpha$ inhibitor infliximab in severe atopic dermatitis. J Am Acad Dermatol 2004; 50: P3.

[11] European Task Force of atopic dermatitis. Severity scoring of atopic dermatitis: the SCORAD Index, consensus report of the European Task Force on atopic dermatitis. Dermatology 1993; 186: 23-31.

[12] Johansson SGO, Bieber T, Dahl R, et al. Revised nomenclature for allergy for global use: Report of the Nomenclature Reviw Committee of the World Allergy Organization. J Allergy Clin Immunol 2004; 113: 832-36.

[13] Lipozencić J, Wolf R. Atopic dermatitis: an update and review of the literature. Dermatol Clin 2007; 25(4): 605-12, $\mathrm{x}$.

[14] Howell MD, Kim BE, Gao P, et al. Cytokine modulation of atopic dermatitis filaggrin skin expression. J Allergy Clin Immunol 2007; 120(1):150-5.

[15] Antunez C, Torres MJ, Mayorga C, et al. Different cytokine production and activation marker profiles in circulating cutaneous lymphocyte associated antigen $\mathrm{T}$ cells from patients with acute or chronic atopic dermatitis. Clin Exp Allergy 2004; 34: 559-66.

[16] Howell MD, Novak N, Bieber T, et al. Interleukin-10 Downregulates anti-microbial peptide expression in atopic dermatitis. J Invest Dermatol 2005; 125 (4): 738-45. 